\title{
The Importance of Social Media for Commerce. A Case Study in Madeira (Portugal)
}

\author{
http://dx.doi.org/10.3991/ijim.v6i1.1825 \\ I. García Medina and P. A. Correia Pereira \\ University of Vic, Barcelona, Spain
}

\begin{abstract}
The continuity and the success of organizations appear increasingly associated with the incorporation of social media. The success depends of the structural and procedural changes that the organization has to make. Today, social media are the new digital marketing tools that help in the processes of communication. Companies need to understand that they are no longer the exclusive owners of the relation of consumers with their products/services; instead, the survival of the organizations depends of the effective utilization of the social media. Creative and innovative solutions are not necessarily too expensive and the internet ends up being one of the best marketing tools available for the organizations. In a more transparent and dynamic world, consumers trust other people to provide advice and recommendations about products and services more and more through social media and it is important to know how and why social media influence organizations. This study analyzes through a literature review the current importance of social media for digital marketing communication and shows a case study on traditional shops that use social media to obtain competitive advantages over shopping centers in Funchal (Madeira, Portugal). To finish, the study proposes a new model of business for successful marketing strategies. Also, the article explains how to manage the changes associated and how collaborators need to get used to working in a wider and more dynamic community.
\end{abstract}

Index Terms-Digital communication, digital marketing, online community, social media.

\section{INTRODUCTION}

Social media have revolutionized the way people communicate and share information between themselves. The consolidation of social media on a daily basis is increasingly intense, although some cases have been highlighted, in particular Facebook. According [8] "The advantage of the competitiveness comes from a technological introduction and the constant adaptation along the time to the technological evolution inserted in the strategy of the organization."

Reference [19] said: "the phenomenon has changed social behaviors and captivated new users, especially in females and senior citizens, who did not use information technologies as much before pre social media when users were overwhelmingly male.” With the emergence of social networks these audiences have developed a greater affinity with digital technologies, having a regular and dynamic coexistence in the virtual world, occupying a prominent place in virtual social interactivity. The participation on a massive scale of thousands of people through- out the world to the phenomenon of social media has contributed to the exponential growth of the various social networking, allowing them to achieve the critical mass necessary for the social media to become an appreciated channel of communication for many organizations.

Reference [21] says that "the use of the on-line phenomenon by organizations involves developing a communication program of integrated marketing, maximizing the individual and collective contribution of all the activities of communication, defining for the virtual channels a program of communication more personnel in the field of direct and interactive marketing”. This will make possible to perceive the role of the communicational marketing in the creation of content and interaction with the customers in the various social platforms such as Facebook, Twitter, Linkedin, Youtube, MySpace, Orkut, blogs and other social networks.

Reference [25] states that digital social networks are the amplifier of internal capabilities of the organization at the level of behavior and technology. To use the "outsourcing" for the management of social networks is a strategy ready to fail because it hands over to third parties what should be the essence of the organization in the creation of competitive advantages to perceive and relate to its target audience. Embarking on interactive marketing in social networks, is not just one more option for communication with customers by copying the actions of the competition. It consists of a deep change in the behavior in the organization. Only the experience and the corresponding temporal allocation reaches to interactions of high level that allow the individual consumer to create unique experiences with the company and it will become the key to new sources of competitiveness.

An approach to transparency and trust concentrated the whole organization, and is an integral part of the activities of management, in particular in the perception of the internal and external environment, the vision and mission, defining and implementing strategies and monitoring. The growing importance of social media as a tool of marketing-mix, has encouraged the expansion of similar technologies, new and powerful on-line applications are to be launched especially in the mobile channel, which will be the main form of access to social networks in the near future, mobility will be driven by devices such as smartphone, e- readers and tablets. According [19]: "the ubiquity of the technology, inherent characteristic of the new tools, the communication between devices, connectivity and the convergence of technologies of information associated with georeferenced location, will contribute to a most enriching experience of the user." 


\section{SHORT PAPER}

\section{The Importance of Social Media for Commerce. A Case Study in Madeira (Portugal)}

Reference [5] states that "the visibility and convergence are moving to a new era of greater transparency and commitment in the relationships individual - individual and individual - organization”. However, the majority of them are still linked to the ranking of their profiles, "how many friends I have in my profile", "who said I like? ", as if that resembled the popularity or fame, how important is this information that is worth as much as the hits of the site in the process of compromising between both sides.

\section{New Model of Business for SuCCESSFul MARKETING STRATEGIES}

The strategic basis for social media is based in a real relationship with people and on the need to eliminate the noise created by the rankings, find out what is important in long-term relationship between the organization and its fans and focus on genuine relationships, honest, lasting and value to both understand who is interested in maintaining a relationship with us and is truly on and react to our presence and actions. Important are those with whom we have a relationship of proximity and interactivity that allows the exchange of views and discussions on common interests, people who actively participate with their opinion on the subject, people who talk about winter sports because they have passion, compliment or criticize you because they live in this community. People are connected by real things and matters of mutual interest rather than rankings.

The difference is about people feeling essential to the relationship. Consequently, "networking" is important when there is a real link for everyone and is a useless distraction when the real connection does not exists, although we are constantly seduced by the image of useless popularity based on the numbers, it is important to know who follows my path and what I would follow them and go after these people and get the privilege of one day be able to gain value from this relationship [21].

Therefore, marketing in social media is not "speak loud" ads to people, but to lead, to do something that captivates and connects people who are interested in a connection with a mutual order. People want to follow someone who is genuine and authentic.

\section{A. Strategy}

The strategic choice is intrinsically integral to the company's success and is based on the selection of one or more strategic alternatives that define the baseline for future actions. Your choice is obviously influenced by the analysis of internal and external environment of the company [9].

When a company defines its strategy, it determines who are the customers it wants to serve (segmentation - target market), what their needs are and how to meet them highlighting their core competencies. The binomial + customers needs, allows the segmentation of the market performance of the company, which will allow full symbiosis between supply and demand, through the segmentation variables. Companies that continuously innovate and improve their skills, can expect to exceed the expectations of consumers over time. The purpose of the strategy is to create differences between the positioning of the company and its competitors through the implementation of its activities in a different form or through the development of activities that competitors do not offer. Consequently, the posi- tion supported by a number of different activities is more than just sustainability supported by an activity, helping the company to establish and operate a certain competitive advantage [9].

The strategic choices are delineated between the cost leadership (produce with less cost than competitors) or differentiation (the ability to differentiate themselves and get a price that covers the cost of differentiation). In the strategy, the logical thinking imposes discipline and simple assumptions that help to identify future scenarios and deduce the favorable strategic solution based on SWOT. When firms do not have any strategy, they usually move in various directions without coordination and without effective sharing of knowledge. In the approach to social media, the organization has also reviewed SWOT analysis, the definition of target market, the organizational objectives for the on-line channel, which is what the organization intends to accomplish with social media? (Spreading the brand, reach new customers or increase sales), assess the resources and time available at the organization to work in social media, to evaluate their on-line presence and active participation in social media.

The strategies are temporary; the companies will progress from one to another according to their tolerance for uncertain outcomes and objectives, as they realize their positioning. In social media the company also evolves in their strategies, understanding the mechanics of the social environment running small actions that will culminate with the full integration of the organization. The use of social media is confined to a specific area such as customer service, when the company intends to take few risks or reduce the uncertainty, using only management of internal resources and use existing tools for measuring results. With more experience and resources, companies start investing a little more, take more risks and use a small-scale test to find ways of improving functions and practices. The aim is to learn by listening to customers and employees on social networking platforms. The evolution brings the development of major initiatives and the allocation of dedicated resources across all departments and extend to external agents (clients and business partners) with the aim of knowing as social media can contribute to business strategy and culture of the company about unpredictable factors and new trends.

\section{B. Segmentation}

For companies it is important to select those who want to serve, as in off-line strategies is important to know which is the group or segment to serve. Use social media marketing requires a different attitude, it is useless to use the same "speak loud" off-line, it is necessary the link between people and the organization, both followers of a common interest.

Behavioral changes manifested by customers in on-line experience are more pronounced, and revealed the need to monitor this behavior as a way to effectively understand the target market at the moment.

The on-line segmentation has focused on the selection of specific population groups with homogeneous characteristics, including the origin of the visitor, who is, what products and services are more seen. Combining these variables it is possible to specify the target segments capable of responding to offers / specific messages. Targeting social networks turns out to have more support ele- 
ments which gave it greater accuracy, a result of the spontaneity of the people in the completion and regular updating of their profile, including records of demographic, geographic, psychographic and behavioral attitudes through their tastes and desires.

The segmentation identified with the actual characteristics of the group, provides a more solid basis for marketing actions, the marketing -mix with that audience can offers most effective results on-line than off-line, in addition to increasing channel options information and marketing communications and the resulting contribution. The greater the match between the needs / desires of consumers in their "target" with the message (marketing mix) of the company, the greater the importance to consumers, increasing their loyalty to the organization / brand and the implementation of identified opportunities.

\section{Marketing Mix}

During the strategy formulation process and ones is complete the determination of general guidelines, is introduced the definition phase of the strategy in terms of marketing variables (tactics).

The aim is, in a pragmatic perspective, to provide tools for analysis and decision support regarding the future implementation of the four variables of marketing mix: product, price, distribution and communication. The variable product may be considered as central in marketing strategy, considering that the pricing strategy is defined taking into account the characteristics and performance of the product, the degree of customer satisfaction and their sales volumes, the distribution strategy is strongly influenced by the characteristics of their products and consumers' purchasing behaviors associated with them, the communication strategy is formed from the features and benefits provided by the product. Nevertheless, to the level of strategy formulation, the variable product does not dominate over the other variables, because the marketing strategy involves decisions in the four variables, firms may allocate more or less importance, selecting those that are essential, acting as engines of development of its offer. The important thing is to formulate an offer that meets the desires and needs of the target market. The marketing communication are the means that companies have to inform and remind consumers to interact (directly or indirectly) about the products / services and brands they sell and is a way to establish a dialogue and relationships with their customers.

Communication has several functions, you can tell how and why the product is used, what kind of people use it, where and when you use it, consumers can know who produces under that mark and may receive an incentive to use it. It allows companies to connect their brands to people, places, events, other brands, experiences, feelings, etc.. And contribute to creating a brand image. It is why social media should be integrated into the marketing - mix strategy relevant to the marketing communications program, maximizing individual and collective contribution of all stakeholders.

\section{Communication}

In communication there are two important objectives, first to alert the recipient of the message, the second time to win their attention. In a world saturated with information and suspicion, to achieve these objectives requires an increased effort. In an analogy economic time for individ- ual attention is a scarce resource for excellence in developed societies in paradox with a growing supply. In this scenario brands need to make a greater effort to achieve more than a little public attention saturated by messages trying to get their attention and less tolerance for invasion of personal space [15].

People are constantly bombarded with contents of consumer marketing, but they are looking for honest interactions with real content. The most important message is one that is passed from one friend to another, which means that marketing needs to ensure that all communication is as open and honest as possible, be authentic and away from bonds that may seem unethical. The technology revolution of the Internet was 2.0, which caused the power center of this economy of attention shifts to the transmitters to receivers who decide how, when, where and to whom attention is given.

Internet, phones, mobile phones, PDAs, digital terrestrial television and other interactive technologies have been democratizing the market communications. Whatever the message the company wants to convey is increasingly necessary to overcome accessibility barriers, context, relevance and seduction of the message to be able to connect to the receiver. The emergence of social networks revives the art of storytelling, storytellers "storytellers" whatever the story / content (movies, advertising, commercial information, company presentation). A good story is playful, sensual and emotional, loaded with meaning, is instructive, because it is non-intrusive by invitation and promotes cohesion, participation and interactivity of your recipients. The brand communication and organizations is matched or unfolds against the backdrop of a teleseries with an unlimited number of chapters [7], [15].

An account of the need to create, plan, feed, protect and update constantly to respond to unrest caused by social media. These information technologies (internet, mobile,...) made the cost of creation, production and cheap distribution of content to the receivers, which ceases to be a passive audience so as to become active participants in communication, deciding on the content and form of the message , modifying it to become co-authors. In this interactivity, the life cycle of the messages is uncontrollable, is no longer a sealed package to become a transformative content, which diffusion is enhanced by on-line channels. We will learn that success will depend on how we tell and how people tell us the reality.

\section{E. Media}

It is difficult for any organization to be present in all social media effectively, therefore, they should select those who may have more value in order to be able to respond appropriately to all requests. It is better to opt for one or a few channels than are available to everyone and do not communicate efficiently and effectively with the selected audience, hence the need for a strategy that defines the channels and the modus operandi for each one and do not follow or to be present just because the competition is there. Selling price is based on a strategy used by many companies in restrictive conditions of inequality and operation of multinational dimension, and therefore, its actions must involve the use of media that differentiate from the larger companies. The idea is to see who in your virtual community and how they feel their presence, who is connected to the company and make a difference by adding value beyond the physical product and price, with 


\section{SHORT PAPER}

\section{The Importance of Social Media FOR COMmerce. A Case Study in Madeira (Portugal)}

shares that may be based on tools provided by social media.

Human beings are naturally social; they want contact with other people in developing different activities from social events up to sporadic coffee. In social media that need is amplified by a community that is constantly creating, sharing, collaborating, commenting, criticizing, etc.. spontaneously. Thus, it is important for the organization to show a human character to your community. Honesty, transparency, loyalty, generosity, respect are adjectives that characterize and solidify the notion of belonging to the community and the satisfaction of basic human need and that makes the difference with the competitors, differentiating it from the way the organization does and why does.

When the company is a supplier guided by the price, people will not talk about it, and not remember it, because it is not well known, limiting their growth prospects. It is important that the organization fosters an attitude of belonging on the part of its target audience, a community where people interact with the organization and feel it as their own, sharing common interests, act as host organizing discussions or events, that indispensable the daily lives of its audience, which makes people feel its lack, is not limited to communication based on price and product, but adding value for its service to the community through a positive attitude (eg Wikipedia - all around an interest free, everyone wants to contribute).

The online presence and degree of interaction of the organizations should have four important factors as guidance on strategy for social media in particular, be found, be authentic, be relevant and be promoted.

Be found by people looking for their products or services, enhancing the presence and content, under terms that are not filtered or refused to assume the position identification with the selected segment. The good companies are mainly aimed at meeting the needs of its customers, using the keywords and descriptions corresponding to the offer.

To be authentic must demonstrate transparency and honesty, allow people to connect and identify with the company / brand. The very notion of community is related to the trust. Connect and commit the necessary help to create community around the business, own business / brand also helps define the people who take (reporting real stories). Companies must become part of the community in order to truly benefit from social media (regularly updated information, new routine messages, listen, respond, question, discuss, discuss, participate in daily life). Social media helps to feel part of a wider community [22].

Be relevant and need to hear and interact with this community, participate where supply is direct value and make the competition irrelevant.

The promotion uses a particular philosophy of viral marketing, an adaptation to internet marketing used to effect word-of-mouth, which can be understood as an advertising message spread by consumers, between consumers, a marketing tool that attracts attention with a view its propagation, videos, photos, podcast, are the operational tools of the communication strategy of viral marketing to social media. Advertising has traditionally been integrated into the exterior of the content (programs, reports, articles, etc.). But now needs to be integrated into the content itself to take advantage of viral marketing opportunities.
All factors should be integrate on social marketing actions and in viral marketing which is part of the growing digital campaigns, using the interactivity of the fans in a free and spontaneous manner (with high levels of credibility), to propagate content related to the organization in various formats, including video, audio and text (eg video clips, pictures, news, blog, media clips, games, news, podcasts, blog articles, discussions). It is important that these contents are simple, easy to propagate, with value to the community, reflecting the company's position and reflect their social position.

\section{Case Study: Consultancy in Social Media as a TOOL TO INCREASE THE COMPETITIVITY OF TRADITIONAL SHOPS}

Each activity of management consultancy has its peculiarities and when we refer to the business of traditional shops is not, of course, different. Moreover, we could say that it will be even more detailed and specific; this is because the shops and the retailers must have a positioning that sets them apart from the competition and that provides a lot of added value. But, that is not what we find in urban centers from around the world; on the contrary, we find a gradual deterioration of traditional shops in these areas.

Reference [8], said: "while the practice of management may not be evolving as fast as it once did, the environment that faces 21st century businesses is more volatile than ever. This new century may still be young, but it has already spawned a sizable brood of daunting managers' challenges that are markedly different from the ones that taxes our forebears; the new reality calls for new organizational and managerial capabilities. To thrive in an increasingly disruptive world, companies must become as strategically adaptable as they are operationally efficient. To safeguard their margins, they must become gushers of rule-breaking innovation”.

The overall studies of marketing on the subject of social media for traditional trade are relative recent, but this does not mean that are not relevant, as reference [12] said: "Internet is a really powerful and inexpensive channel for communication, distribution and sales". Also reference [21] explains that before the web, companies used the media only for promotion, but with the Internet, companies use the media to develop relationships with customers.

The problem is that it is necessary to know how to use digital social media in order to take advantage of them and before to arrive to this stage it is necessary to resolve some problems from traditional shops. But, there are the well applied and successful consultancy cases in digital social media, which indicates that problems in this area can be resolved.

In addition to outdated traders, there are problems of succession, problems of geomarketing, a lot of stocks accumulated and old fashioned shops, outdated sales techniques, wrong promotion ideas, a counter-productive relationship with customers and suppliers, and there is still a most remarkable feature, which shows us the need for action: the current changes in consumer behavior.

During the one year period between 15 March 2010 and 15 March 2011, 128 traditional shops were analyzed in Funchal, (Madeira, Portugal), after the analysis and the suggestions made by consultants, more of $85 \%$ changed 


\section{SHORT PAPER}

\section{The Importance of Social Media for Commerce. A Case Study in Madeira (Portugal)}

the "rules of the game", achieving more sales and having, also, better perspectives and conditions to ensure competitivity.

After several experiences (training in the operating room, physical changes in shops, etc.) we have concluded that the system of training/action consultancy is the most effective and modern form of making a traditional shop competitive.

It all starts with a visit to the shops and the involvement of tenant shopkeepers in the renovation project which reduce the resistance to change. Then, diagnoses were carried out, delivering practical actions suggestions and helping the shops with extensive useful and sophisticated studies.

In this type of project there is a set of common goals that should respect the different variety of the shops which, in addition to the type of learning and style of each consultant, generates interesting results. In parallel, training actions were carried out in order to increase the competency of all the employers and collaborators.

In this sense, Facebook pages of the shops in accordance with strategies previously defined with the employer were designed, also they participated in Youtube, the shops were included in Google Adwords, and marketing emails and SMS were generated for the companies.

An e-commerce platform was created, converting the nortmal traditional shops into a virtual commercial shopping centre and facilitating networking.

More solutions were developed but their viability will depend of the interest of the companies in their application and of the number of shops that will adopt it.

\section{Conclusions}

The physical and digital worlds are increasingly linked, socialization and human relations decreases their physical dependence on connecting people around the world from different ethnicities and beliefs, a result of increased connectivity and convergence of information and mobile technologies, allowing to be online regardless of geographic location and therefore to act and to have access to information on social networks in real time.

Many companies start realizing that the number of fans on their pages is not synonymous with success in social media, the value is not the number of fans in their communities but the compromise between people and the company increased by social networks. Consumers are no longer passive, they are taking an active role in organizational communication, so organizations need to adopt a culture of inter-relational customers, based on trust and transparency, the numbers will come as a result of this work, but if companies have no idea of this relationship, they do not know what they are doing in social networks.

There is a progression in the development of standards of transparency on-line. Consumers will manage and share their data with trading partners, making it a viable business model.

The major social players (Amazon, Google, Facebook) accumulate individualized information about each of their users in four groups of variables of marketing segmentation: demographic, geographic, psychographic and behavioral. In order to optimize the selection and provision of information customized to the individual profile, this customization can be extended to other areas of business and other businesses cut superfluous information received by consumers, which increase the efficiency and effectiveness of traditional marketing to social media. New applications for the various social and mobile platforms will tend to a high customization, increasing the link between organizations and customers, this will provide increased communication effectiveness of on-line advertising with a social and interactive nature of the on-line marketing, viral and "worth of mouth" with a growing consumer participation in organizational communication. Obviously, collaborators need to get used to working in a wider and more dynamic community and specially the traditional shops will need to adapt to this new way of trading, as well as we show in our study, specific consultancy can be a helpful tool for these companies.

This is only is a way to maintain a competitive edge over franchises and global commerce through the development of a personal and close relationship with customers, but also traditional shops benefit from ideas, comments and feedback of their "prosumers" (producer + comsumer) [24].

\section{REFERENCES}

[1] D. Barefoot, and J. Szabo, "Friends with Benefits, A Social Media Marketing Handbook”, San Francisco, CA: No Starch Press, Inc., 2010.

[2] J. L. Belio, "Conozca el nuevo Marketing: el valor de la información”, Madrid: Especial Directivos, 2007.

[3] E. Brynjolfsson, and A. Mcafee, "Investing in the IT that makes a competitive difference", USA: Harvard Business Review, JulyAugust 2008, pp. 98-107.

[4] E. Butow, and K. Taylor, "How to Succeed in Business Using LinkedIn: Making Connections and Capturing Opportunities on the Web's", NY: Business Networking Site, Amacom books, 2009.

[5] P. Dunay, and R. Krueger, "Facebook Marketing for Dummies", Indianapolis: Wiley Publising, Inc., 2010.

[6] S.Godin, “Tribes”, USA: Piatkus Books, 2008.

[7] S. Godin, “All Marketers Are Liars: The Power of Telling Authentic Stories in a Low-Trust World”, USA: Penguin Group, 2009.

[8] Hamel, G"The future of management”, Boston: Harvard Business School Press, 2007.

[9] M. Hitt, R. Hoskisson, and R. Ireland, “Management of Strategy”, London: Thomson Higher Education, 2007.

[10] H. Jenkins, "Convergence Culture: Where Old and New Media Collide”, New York: New York University Press, 2008.

[11] T. Kelsey, "Social Networking Spaces, From Facebook to Twiter and Everything in Between", NY: Apress, 2010.

[12] P. Kotler, K. Keller, M. Brady, M. Goodman, and T. Hansen, “Marketing Management”, USA: Pearson Education Limited, European Edition, 2009.

[13] C. Li, and J. Bernoff, "Groundswell: Winning in a World Transformed by Social Technologies”, USA: Harvard Business School Press, 2011.

[14] M. Miller,” Facebook for Grown-Ups”, Indianapolis: Pearson Education, Inc., 2011.

[15] A. Núñez López, “Será mejor que lo cuentes”, Spain: Empresa Activa, 2009.

[16] J. Peppard, and J. Ward, "Beyond strategic information systems: Towards an IS capability", Bedford: Journal of Strategic Information Systems, n. 13, pp. 167-194, 2004. http://dx.doi.org/10.1016/ j.jsis.2004.02.002

[17] J. Peppard, and J. Ward, "Unlocking Sustained Business Value from IT Investments”, CA: California Management Review, vol. 48, , pp. 52-70, 2005.

[18] C. Prahalad, and V. Ramaswamy, "Co-creation experiences: The next practice in value creation", USA: Journal of Interactive Marketing, vol.18, ed. 3, pp. 5-14, 2004. 


\section{SHORT PAPER}

The Importance of Social Media for Commerce. A Case Study in Madeira (Portugal)

[19] E. Qualman, "Socialnomics: How Social Media transforms the way we live and do business”, USA: Wiley Publishing, 2009.

[20] P. Schubert, and U. Leimstoll, "Importance and use of information technology in small and medium-sized companies”, Leipzig: Electronic Markets, vol. 17, pp. 38 -55, 2007. http://dx.doi.org/ $\underline{10.1080 / 10196780601136799}$

[21] D. Scott, “The new rules of marketing and PR", NY: John Wiley \& Sons, Inc, 2010.

[22] D. Tapscott, and A. Williams, "Wikinomics: How mass collaboration changes Everything”, London: Atlantic Books, 2008.

[23] M. Tarafdar, and S. Gordon, "Understanding the influence of information systems competencies on process innovation: A resource-based view”, Toledo: Journal of Strategic Information Systems, vol. 16, pp. 353-392, 2007. http://dx.doi.org/10.1016/ j.jsis.2007.09.001

[24] A. Toffler, “The third wave”,USA: Plaza \& Janes, $1980 .$.
[25] H. Wilson, P. Guinan, S. Parise and B. Weinberg, "What's Your Social Media Strategy?”, USA: Harvard Business Review, vol.89, n. 7/8, 2011.

\section{AUTHORS}

I. García Medina is with the University of Vic, Sagrada Familia, 7, 08500 Barcelona, Spain (e-mail: irene.garcia2@uvic.cat).

P. A. Correia Pereira, is with the University of Vic, Sagrada Familia, 7, 08500 Barcelona, Spain (e-mail: pacorreia4@gmail.com).

This work was developed between 15 March 2010 and 15 March 2011 as part of the project "+Comercio" financed by the European Social Fund (ESF) through the operational program RAM-RUMOS (Code: 436/2009/123). Cost: 1,1 M €. Received 27 September 2011. Published as resubmitted by the authors 14 December 2011. 